\title{
Historical development of IEQ in Danish dwellings - has energy efficiency requirements inhibited positive IEQ developments?
}

\author{
Lasse Rohde ${ }^{1, *}$, Tine Steen Larsen ${ }^{1}$, Rasmus Lund Jensen ${ }^{1}$, Kim Trangbæk Jønsson ${ }^{1}$, and Evangelina Loukou $^{1}$ \\ ${ }^{1}$ Department of Civil Engineering, Aalborg University, DK-9220 Aalborg, Denmark
}

\begin{abstract}
This paper investigates developments in indoor environmental quality and energy efficiency over the last 150 years. Sixty-one Danish multi-storey dwellings were registered and scored using a newly developed indoor environment assessment tool called IV20. An overview of these results is presented, leading to an indication of which issues seem to be solved, which remain unsolved, and which new ones have arisen. These indoor environmental quality developments are then compared to developments in energy consumption, to test the hypothesis that some initiatives to reduce energy consumption has come at the expense of occupant comfort and health. An overview of energy efficiency developments for Danish multi-storey dwellings is given through analysis of data from the Danish energy labelling database. The results show a very strong positive development within energy efficiency and a very modest improvement in indoor environmental quality. This results of this research show that we have made huge improvements in energy efficiency without lowering the overall indoor environmental quality. However, the very modest IEQ improvement also indicate that IEQ improvements have been inhibited by energy efficiency initiatives and that further IEQ advances may depend on a shift of focus.
\end{abstract}

\section{Introduction}

The European Union's 2020 and 2050 targets for the reduction of energy consumption and $\mathrm{CO}_{2}$ emissions [1] signal major changes for the building sector responsible for almost $40 \%$ of the global final energy consumption and total greenhouse gas emissions [2]. This political agenda has enforced energy-saving practices into national building codes in the developed world heavily influencing how we build and renovate. In some cases, this focus on energy efficiency has been at the expense of healthy and comfortable indoor environments (IE) [3]. Increasing insulation values, air tightness, and passive solar gains often result in extensive overheating [4-6].

In many parts of the world, people spend $90 \%$ of their time in doors [7]. Most of this time is spent at home, meaning that IEQ in dwellings has a large impact on the comfort, health and well-being of people. The social sustainability potential of good indoor environmental quality (IEQ) in dwellings is huge from perspectives such as work absenteeism, productivity, healthcare costs, and social equality. Thus, it may be the time to complement political agendas such as the Energy Performance of Buildings Derective [8-9], with an ambition to also improve IEQ in dwellings. There is a growing political understanding that energy efficiency and IEQ should not be seen as mutually exclusive [10-11].

The rapidly increasing world population adds extra pressure to climate adaption requirements and acts as a driver for increased urbanization as this is the modern answer high population accommodation and sustainable living. Increased urban density leads to increased exposure to noise and air pollution reducing the potential of a healthy and comfortable indoor environment. When buildings are too tall and to close it also compromises privacy from risk of unwanted view in, and reduce access to daylight, sunlight, and view out. United Nations expects two-thirds of the world's population to be located in urban centers by 2050 [12]. This means that the development of urban dwellings, with low-energy consumption and high-quality indoor environment is one of the keys to sustainable living in the decades to come.

The Energy Performance of Buildings Derective [8-9] has resulted in energy labelling for European buildings as part of the building code. Many national variations of energy efficiency assessment tools (Be18 in Denmark) calculate a theoretical energy demand for both existing and new buildings. As a result, energy-efficiency databases for buildings are well developed in a European context. However, most IEQ assessment tools are designed for evaluating new buildings only or are expensive certification options for best practice buildings (such as LEED, BREEAM, DGNB), meaning that developments in overall IEQ are mostly unknown - particular for older dwellings.

The REBUS project [13] has developed an IEQ assessment tool called IV20 based on simple-input calculations, as opposed to expensive and timeconsuming measurements and occupancy surveys. The independence of measurements and surveys removes bias from user responses and user behavior and enables

\footnotetext{
* Corresponding author: ler@,civil.aau.dk
} 
assessments of IEQ potential in both existing builds and unrealized design proposals. This makes the tool ideal for benchmarking samples of the existing building stock.

This paper will compare decades of well-documented positive developments in calculated energy demand, with new data on the developments in potential IEQ in dwellings. IEQ assessment results of 61 multistory dwellings will be presented, followed by a brief discussion of the main trends. IEQ developments are then compared to overview plots from energy labelling database extracts (Energistyrelsen - Danish energy label database) to compare developments within IEQ and energy efficiency over time. Based on this analysis, the authors will highlight tendencies in how the building code emphasis on energy efficiency has affected the overall IEQ for multistory buildings in the last 150 years.

\section{Methodology}

\subsection{Categorizing cases into building periods}

The analysis of Danish multistory dwellings is based on IEQ assessments of a series of selected case studies compared to analysis of energy labels for multistory dwellings. This paper will use the building typology scheme TABULA [14] to organize the buildings into time periods separated by building tradition shifts, that affects building typologies in a Danish context from 1851 and onwards. Many of these shifts are energy-consumption driven, and thus defined by the introduction of building codes with increasingly strict energy requirements. This paper investigates how energy-consumption driven requirements have affected the potential IE in multistory buildings by comparing the advances in energy efficiency (using the national energy label database) with changes in IEQ in the cases assessed.

It is outside the scope of this paper to explain the differences in the individual building code requirements, but since the introduction of the first Danish energy requirements in 1961, the focus has been on limiting energy consumption for heating. This has primarily been done through improved insulation levels and later through heat recovery of exhaust air and improved air tightness. Since the '98 building code, there has been a focus on increasing passive solar gains, primarily through increased glazed areas, window orientation optimized for solar gains, higher window g-values and lately requirements for fulfilling E-ref requirements. These changes are expected to have influenced the indoor environment on several levels, in particular, thermal IE which is directly tied to heating demands, but also for visual IE and IAQ as a result of changed window areas, new window properties and the introduction of mechanical ventilation. The analysis of the IEQ assessed cases would focus mainly on thermal IE, visual IE and IAQ, as many energy-efficiency initiatives influence air change rates, daylight conditions, or thermal comfort variations.

\subsection{Sampling and data collection procedure}

Sixty-one Danish multifamily dwellings were rated using the IV20 tool for assessment of IEQ in multistory dwellings. The cases were selected on three criteria to ensure good representation of the Danish multistory dwelling building mass with the available resources;

1) Location within one of the largest Danish cities (see introduction for increased urbanization arguments),

2) Year of construction spread across as many building code periods as possible (minimum 5 cases for each period to be included in the analysis),

3) Availability of drawings and access to the dwellings.

Registrations were made in November/December 2017 by a team of three assessors to minimize the risks of variations in the use of the tool. All dwellings were registered through a combination of on-site registration, analysis of drawings and online sources. The on-site registration was performed using a registration template organized for systematic registration of IV20 input on site level, building level, dwelling level and room level. The online sources include building project archives, aerial photographs, and digital maps for site-specific traffic noise and pollution levels.

\subsection{Building periods, Building codes and Energy labels}

The cases registered covers 8 of the 10 Danish energyrelated building typologies (the Danish contribution to the TABULAH project, SBi2012:01 (Wittchen \& Kragh, 2012). The period before 1851 is not included as it has no/very few multistory cases and no energy labels before 1851, while the 2007-2011 period was excluded for IEQ assessment as it was not possible to obtain access to at least 5 cases. The IEQ cases cover buildings constructed range from 1883 to 2016 (134 years), and is split between 3 of the 4 largest Danish cities as follows; Aalborg area 27 cases, greater Copenhagen area - 23 cases, and greater Aarhus area -11 cases. Year of construction ranges for the periods are as follows: 1851-1930 (period 1); 1931 1950 (period 2); 1951 - 1960 (period 3); $1961-1972$ (period 4); 1973 - 1978 (period 5); 1979 - 1998 (period 6); 1999 - 2007 (period 7); 2007 - 2011 (period 8); 2011 . onwards (period 9).

Building energy labels were extracted from the national energy label database (Energistyrelsen) for the 179280 multistory dwellings in the period from 1851 to 2015 (165 years). The analyzed energy labels span across the 9 different Danish building periods listed above. Period 4 is marked by the introduction of the first energy requirements in BR61, with the period 5-9 range being defined by increasingly tightened requirements for BR72, BR77, BR98, BR08 and BR10. 


\section{Results}

\subsection{IV20 cases - IEQ overview}

Figure 1 shows the IV20 score for air quality, thermal IE, and visual IE respectively, for each of the 61 registered cases listed by year of construction. Note that acoustic IE is also part of IE assessment in the IV20 tool, but has been omitted from this analysis as this paper compares developments in IEQ with improvements in energy efficiency. Energy efficiency improvements driven by building code requirements mainly influence performance for air quality, thermal IE and visual IE, but has little effect on acoustic IE. The three areas analyzed contribute equally to the overall IV20 scores shown for this paper.

\subsubsection{Overall IEQ tendencies}

The data in figure 1 shows a tendency (highlighted by the trend line) towards a modest improvement in IEQ over time. The earliest period (1851-1930) has the lowest average IV 20 score of 62 pts (out 100 pts), while the most recent period (2011-2015) has the highest average of approx. 73 pts. The improvements over time are relatively small compared to the differences between individual cases, however, such as the 1973-1978 period containing both the lowest of all scores at approx. 49 pts as well as a score of approx. 73 pts positioned in the top third. The large inter-period variations suggest that IE variations are more dependent on case-specific conditions than the requirements of the applied building code at construction. The large variations within building periods call for greater sample size, allowing for further statistical analysis. However, a tendency for the development can still be found in the analyzed cases.

\subsection{Energy labels - Energy-efficiency}

Figure 2 shows developments of energy efficiency for multifamily dwellings over the last 165 years, by plotting averaged primary energy demand by construction year (using primary energy factors from BR10). The data plotted comes from the Danish energy labelling database, and includes 179,280 Danish multifamily dwellings constructed between 1851 and 2015 .

\subsubsection{Overall energy-efficiency tendencies}

The data in figure 2 shows a clear tendency (highlighted by the trend line) in decreasing energy demands over time, particularly from 1961 to 2015, with a factor 2.63 improvement (averaged yearly energy demand in $\mathrm{kWh} / \mathrm{m}^{2} /$ year; period 3: 117.8 and period 9: 44.8). While the average energy demand is unchanged for the first 100 years analyzed (averaged yearly energy demand in

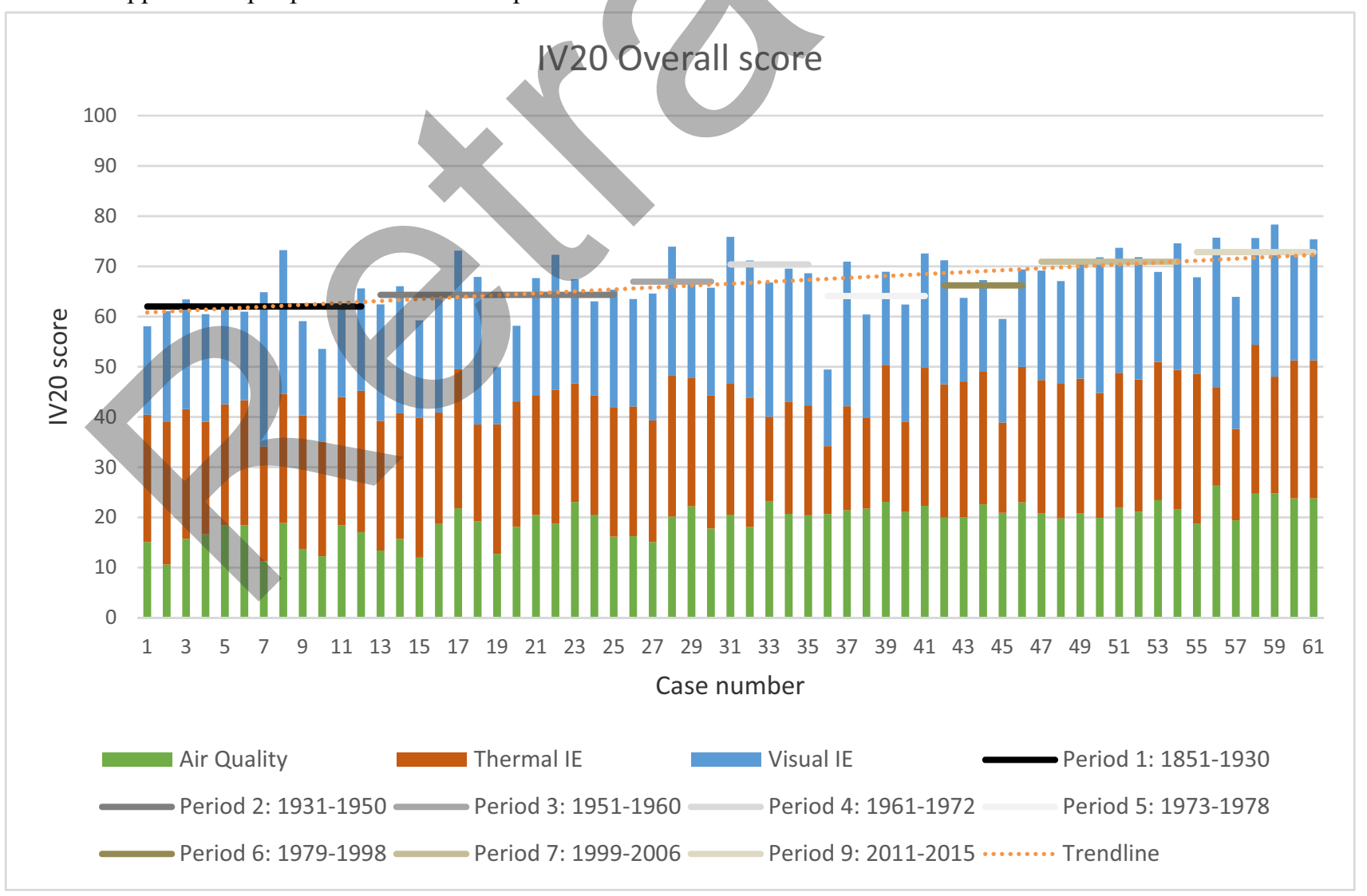

Fig. 1. IV20 score for 61 registered multifamily dwellings (chronologically ordered by year of construction) showing contributions from air quality, thermal IE, and visual IE, as well as averaged values for eight different building periods. 


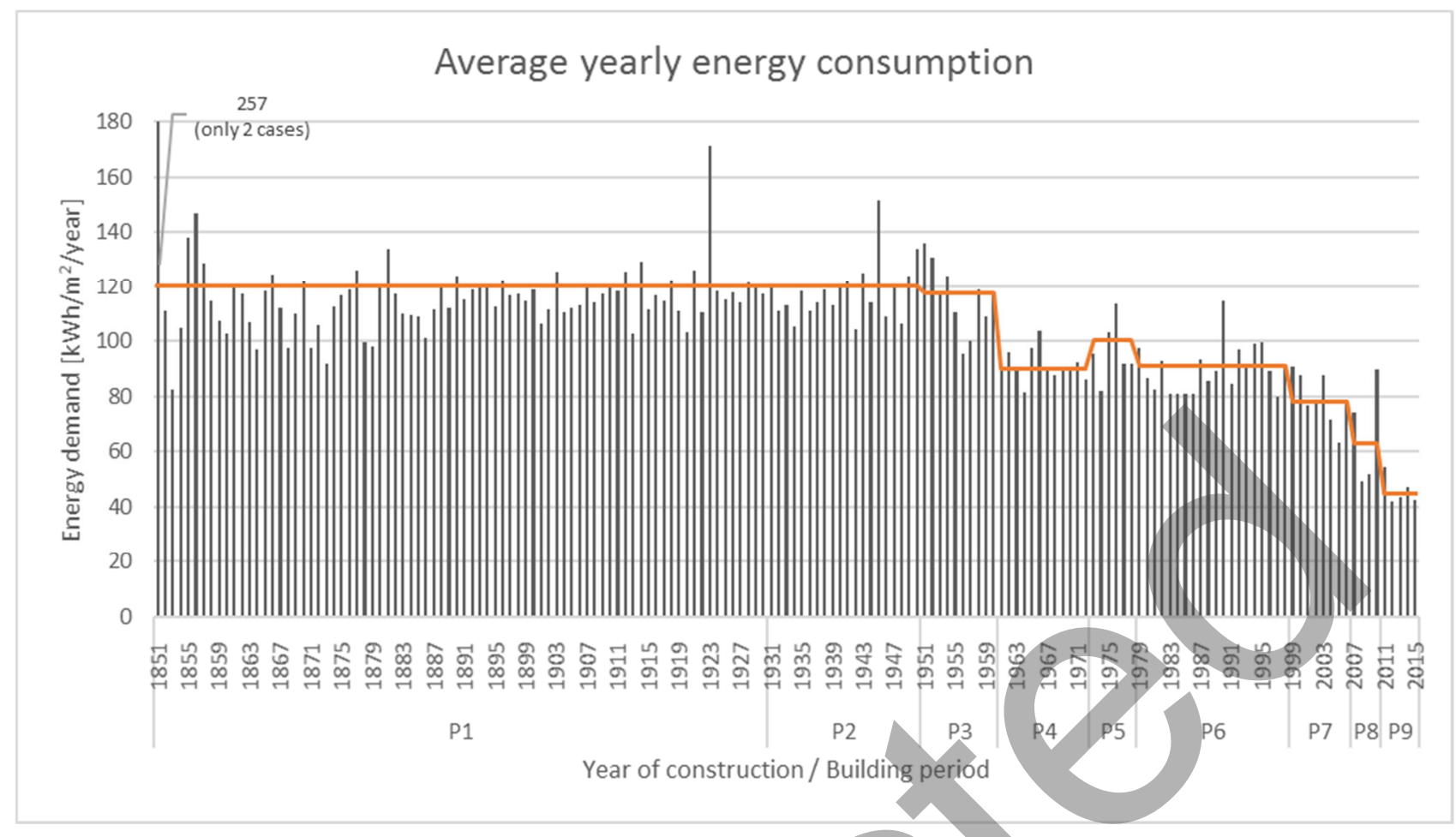

Fig. 2. Calculated primary energy demand for 179,280 Danish multifamily dwellings plotted as averaged values by year of construction from 1851 to 2015 . The orange curve shows time period averages for nine different building codes.

$\mathrm{kWh} / \mathrm{m}^{2} /$ year; period 1: 120.2 , period $2: 120.3$, and period 3: 117.8) it has dropped dramatically in the most recent 50 years. The most significant drop is the almost $25 \%$ drop from period $3\left(1951-60: 117.8 \mathrm{kWh} / \mathrm{m}^{2} / \mathrm{y} e a r\right)$ to period 4 (1961-1972: $90.3 \mathrm{kWh} / \mathrm{m}^{2} /$ year), where the first energy requirement was introduced with the BR61 building code.

Energy demand reduction has been a significant focus in the most recent Danish building codes, which is reflected in an increasingly lowered energy demands for period 7, 8 and 9 (1999-2015). The average energy demand by construction year is effectively halved in just two decades from 91.2 to $44.8 \mathrm{kWh} / \mathrm{m}^{2} /$ year with the introduction of the BR98, BR08 and BR10 building codes.

Going further back, we get a factor 2.69 improvement of the average energy demand by period between the $1931-1950$ period $\left(120.31 \mathrm{kWh} / \mathrm{m}^{2} /\right.$ year $)$ and the $2011-2015$ period $\left(44.78 \mathrm{kWh} / \mathrm{m}^{2} /\right.$ year $)$. When comparing this to the modest factor 1.13 improvement (64.3\% in $1931-1950$ period, to $72.8 \%$ in the $2011-2015$ period) in indoor environment in the same period (as exemplified by the IV20 score in Fig. 1) it becomes very clear that the building code requirements has prioritized energy efficiency above indoor environmental improvements.

\subsection{IV20 cases - IEQ area by area}

More than two-thirds of the 10.8 pts overall IV20 score increase over time can be accredited to IAQ improvements, with an overall score contribution ranging of 15.5 pts from the earliest period (1851-1930) to 23.1 pts in the latest period (2011-2015) (see Fig. 1). The rest of the overall seore increase if from a slight improvement in visual IE ranging from 21.2 pts from the earliest period (1851-1930) to 24.7 pts in the latest period (2011-2015). Thermal IE shows no improvements over time, with an average overall contribution of $25.2 \mathrm{pts}$ from the earliest period (1851-1930) to $25.1 \mathrm{pts}$ in the latest period (20112015 ) and an average of 24.7 pts across all time periods.

\subsubsection{Tendencies - IAQ}

Although modest, air quality improvements are relatively stable across all periods, with the most significant improvements in the range of period 1 through 4, and again from period 7 to 8 . The main reason for the positive development in the early periods are due to air change improvements (IAQ2 in Fig. 3 below), through improved conditions for natural ventilation. The boost from period 7 to 9 comes from the introduction of mechanical ventilation with fixed ventilation rates in the later time periods ( 7 out of 10 cases with mechanical ventilation is from the most recent period, 2011-2015) improving scores for both air change and particular matter in intake air (IAQ2 and IAQ1 in Fig. 3 below).

Decreased adverse effects of air polluting indoor activities, make a small contribution to the overall IAQ improvements, although the two most recent time periods indicate a small step back. The positive part of this development comes from preinstalled components with a beneficial influence on the IAQ such as stove type (combustion-based vs electric), and exhaust hood availability and efficiency. The recent negative development is due to fewer modern apartments (1999+) 
having covered spaces for drying clothes which results in increased particle and humidity loads.

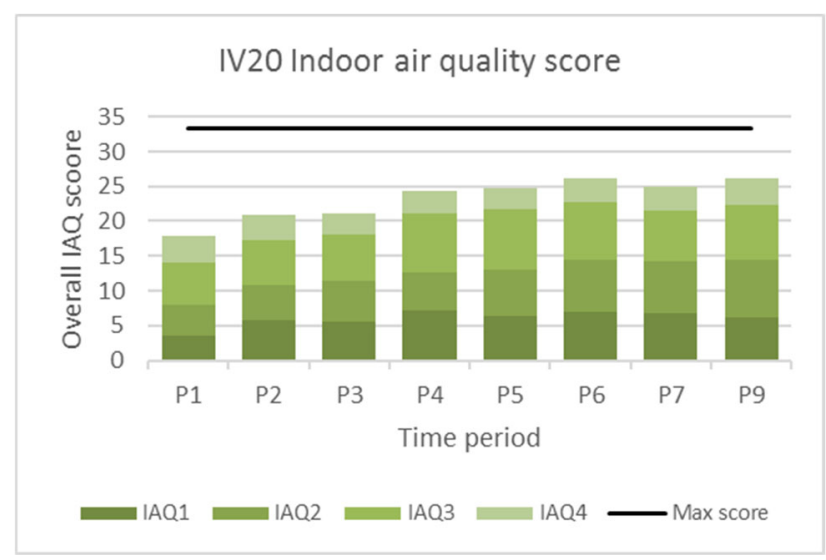

Fig. 3. Averaged overall IAQ score for eight different periods, showing contributions from four different IAQ areas.

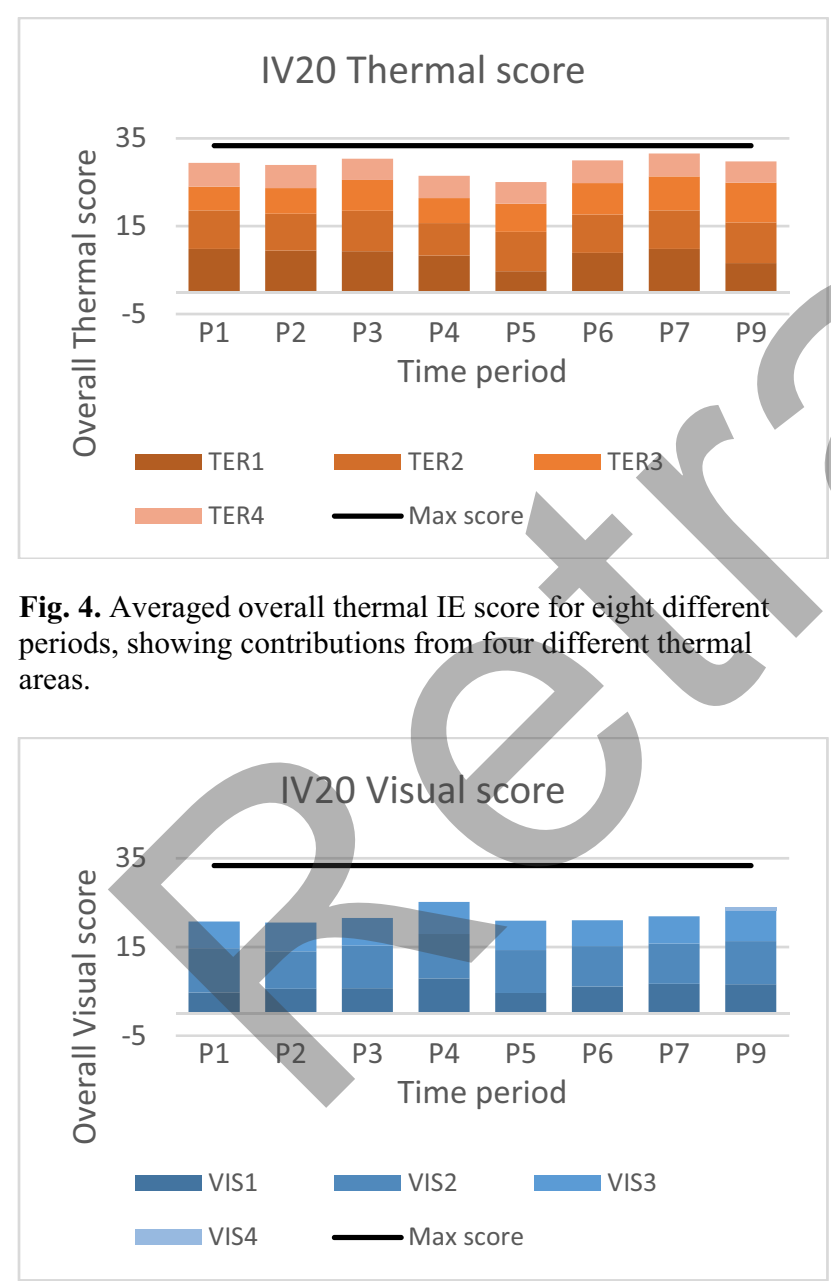

Fig. 5. Averaged overall visual IE score for eight different periods, showing contributions from four different visual areas.

\subsubsection{Tendencies - Thermal IE}

The data shows no overall thermal IE improvements throughout more than 150 years, despite advances in envelope air-tightness and insulation levels. Interestingly, 7 out of 8 cases with an overall thermal score below 20 pts are constructed within the last 50 years (period 4-9; 1961-2015). The reason for these lacks of improvement is primarily due to issues with too high summer temperatures (evaluated through a summer comfort calculation) (TER1 in Fig. 4 below), that is almost nonexisting until energy requirements were introduced in the 1961 building code. Issues with high temperatures are the direct result of building code demands to lower energy consumption for heating; heating demand reduction initiatives (such as reductions in infiltration, line loss and lowered U-values for walls and windows) and passive heat gain strategies (such as heat recovery and increased solar gains). Analysis of the IV20 cases shows that areaweighted average U-values in the first three periods (1851-1960) is 0.91. After 1961, however, the average Uvalue decreases steadily by period down to 0.24 for cases in the latest three periods (1979-2015).

These issues offset the positive developments in winter comfort (TER3 in Fig. 4), mainly from a lowered risk of drafts from improved air tightness and a lowered risk of downdraft from significantly lowered window Uvalues, ranging from 2.5 in the first two periods (18511950) to approx. 0.8 in the latest period (2011-2015). Improvements from pre-heated intake air (here mainly from mechanical ventilation with heat recovery) make a substantial difference in the most recent period (20112015 ) resulting in the best winter comfort sub-scores.

\subsubsection{Tendencies - Visual IE}

Visual IE shows modestly increasing scores over the analyzed time periods, with period 4 (1961-1972) breaking the overall tendency by being the highest scoring period by a margin. This development is reflected clearly in the daylight assessment (VIS1 in Fig. 5), showing daylight quantity and distribution improving gradually over time, but with period 4 (1961-1972) being far above the trend line and period 5 (1973-1978) being far below. The VIS1 sub-score for daylight quality (color falsification) puts a dampener on the positive developments in daylight score, by penalizing projects with a sub-par color rendering (Ra-value). More than half of the projects in period 5, 7 and 9 are penalized for color falsification (12 out of 21 projects), compared to just 1 in 20 for the other time periods ( 2 out of 40 cases). The main part of this color falsification comes from window coating or film (low g-value) designed to fight too high temperatures by limiting the passive solar gains.

The developments in daylight are explained mainly by an increased glazed area starting with a window to wall area of $28 \%$ in the first two periods (1851-1951) to $41 \%$ for period 3-9. Tendencies are less clear for the other visual IE assessment topics such as Positive solar exposure (VIS2), View out quality and View in risk (VIS3), and they will not be discussed in this paper. 


\section{Discussion}

The presented data for IEQ assessment is limited by the modest sample size. The IV20 tool was developed for early-stage assessment of renovation potential of multistory dwellings, but could potentially contribute to future labelling of IEQ of all Danish dwellings. Although the assessment is based on simple input large quantity registration is time-consuming, and it will require mandatory IEQ labelling to achieve a sample size comparable to the almost 180,000 energy labels used for the energy efficiency analysis. The IEQ assessment is made using a beta version of the IV20 tool. While the assessment methodology and criteria of interest are set, the inter-area weightings and scoring may change slightly in the final version.

The IV20 tool is designed to assess the current conditions of a building, but for the historical perspective analysis of this paper, it would be more appropriate to 'reset wear and tear' to the time of erection. Thus, deteriorated window sealants can negatively influence the score for drafts in older buildings, but the influence on the scores presented here is negligible.

Most of the older cases have been renovated, and in cases of recent and deep renovations, this may blur the results of both the IEQ and energy efficiency analyses slightly. For the present comparison of IEQ vs energy efficiency, this has very little influence, as the number of deep energy renovations is relatively small (average calculated energy demand for all renovated projects is approx. $107 \mathrm{kWh} / \mathrm{m}^{2} /$ year vs approx. $105 \mathrm{kWh} / \mathrm{m}^{2} /$ year for non-renovated projects).

\section{Conclusion}

The analyses of the energy labelling database show a strong positive development within energy efficiency in the last approx. 50 years, boasting a factor 2.63 improvement in the average calculated energy demand from period 3 to period 9. The majority of this improvement is in the last approx. 37 years from a tightened energy requirement in 1978 , with a factor 2.24 improvement from period 5 to period 9. This tendency follows tightened legislatorial demands from the introduction of the first building code energy demands (period 4), to a series of ambitious national energy frame reductions still being implemented.

IEQ assessments of the 61 cases indicate a very modest improvement in overall IEQ over time. This research shows that the average level of the main IEQ areas has not declined and that IAQ has improved slightly over time. Analysis on parameter level shows that IAQ has been positively affected by ventilation strategy changes, supporting improvements in ventilation rates for natural ventilation, bathroom ventilation and the introduction of mechanical ventilation with filtering for newer buildings. Thermal IE has been affected by heat demand reduction initiatives, resulting in reduced comfort issues with drafts, but increased issues with over temperature. Visual IE has mainly been affected by larger glazed areas and different window components, contributing to improved daylight levels, but also a color falsification that negatively affects the quality of daylight and view out.

The presented results indicate that the most recent building tradition has managed to improve energy efficiency without negative consequences for the indoor environment as a whole. We have significantly reduced issues with drafts, improved daylight access, and increased dilution and air filtration. However, larger window areas have introduced challenges such as exposure to view in and color falsification through coated glass, as well as large issues with over temperature.

The average percentile improvement of IEQ over 150 years $(+13 \%)$ is more than a magnitude lower than for energy efficiency $(+169 \%)$, fueled by decades of political and legislatorial priorities. While the average overall IEQ has not declined over the last 150 years, this study indicates that the priorities of the building industry have inhibited the positive develops in IEQ. If urbanization is the solution to increasing world population and energy conservation for living and transportation, then multistory dwellings have a considerable influence on the comfort and health of future generations - and should be a topic of interest for architects, engineers and politicians.

\section{Acknowledgements}

The authors would like to thank Energistyrelsen for providing data on calculated energy demands, and Himmerland Boligforening for providing access to many of the registered dwellings. Also, thanks to the master students at Aalborg University who worked with the original registration of the 61 cases; Aurelian Paduraru, Julius César Peralta Hedin and Rasmus Samuel Thode Christensen.

\section{References}

1. European Commission, A Roadmap for moving to a competitive low carbon economy in 2050, 2011. doi:10.1002/jsc.572.

2. International Energy Agency: Buildings, (n.d.). https://www.iea.org/buildings/ (accessed December 19, 2018).

3. C.A. Roulet, F. Flourentzou, F. Foradini, P. Bluyssen, C. Cox, C. Aizlewood, Multicriteria analysis of health, comfort and energy efficiency in buildings, Build. Res. Inf. (2006). doi:10.1016/0096-3003(92)90126-L.

4. C. Brunsgaard, P. Heiselberg, M. -a. Knudstrup, T.S. Larsen, Evaluation of the Indoor Environment of Comfort Houses: Qualitative and Quantitative Approaches, Indoor Built Environ. 21 (2012) 432451. doi:10.1177/1420326X11431739.

5. T.S. Larsen, O. Daniels, R.L. Jensen, M.R. Andersen, EnergiParcel-Projektet: Målinger og analyse af energiforbrug og indeklima i 4 danske parcelhusrenoveringer 2008-2011, Department of 
Civil Engineering, Aalborg University, Aalborg, 2012.

http://vbn.aau.dk/en/publications/id(89900302-

878c-43f6-bb46-741dc39bfa0a).html (accessed December 21, 2018).

6. C. Morgan, J.A. Foster, ; T Sharpe, ; A Poston, OVERHEATING IN SCOTLAND: LESSONS FROM 26 MONITORED LOW ENERGY HOMES, in: J.-L. Scartezzini (Ed.), CISBAT, Lausanne, EPFL Solar Energy and Building Physics Laboratory, Lausanne, 2015: pp. 167-172. https://infoscience.epfl.ch/record/213311/files/2 M ORGAN.pdf (accessed December 21, 2018).

7. N.E. KLEPEIS, W.C. NELSON, W.R. OTT, J.P. ROBINSON, A.M. TSANG, P. SWITZER, J. V BEHAR, S.C. HERN, W.H. ENGELMANN, The National Human Activity Pattern Survey (NHAPS): a resource for assessing exposure to environmental pollutants, J. Expo. Anal. Environ. Epidemiol. 11 (2001) 231-252. doi:10.1038/sj.jea.7500165.

8. Council of the European Union, Directive 2002/91/EC of the European Parliament and of the Council of 16 December 2002 on the energy performance of buildings, Off. J. Eur. Union. (2002). doi:10.1039/ap9842100196.

9. European Parliament, Directive 2010/31 EU EPBD-recast, (2010) 23.

10. K.J. Watson, Developing wellbeing valuation practices in the built environment, CIBSE ASHRAE Tech. Symp. Loughborough, UK 5-6 April 2017. (2017) https://www.researchgate.net/publication/31841924 2_Developing_wellbeing_valuation_practices_in_t he_built_environment.

11. CIBSE, TM52: Evaluating operational energy performance of buildings at the design stage, 2013. https://www.cibse.org/Knowledge/knowledgeitems/detail?id=a0q2000000817f7AAC (accessed December 19, 2018).

12. United Nations, World Urbanization Prospects: The $2014 \quad$ Revision, 2014. https://esa.un.org/unpd/wup/publications/files/wup 2014-report.pdf (accessed December 19, 2018).

13. REBUS, REBUS - REnovating BUildings Sustainably, (2015) 1-133.

14. IEE Project TABULA, (n.d.). http://episcope.eu/ieeproject/tabula/ (accessed December 21, 2018). 